Available online on 15.9.2018 at http://ujpr.org
Universal Journal of Pharmaceutical Research
An International Peer Reviewed Journal
Open access to Pharmaceutical research
Commercial Share Alike 4.0 License which permits unrestricted non commercial use,
provided the original work is properly cited
Volume 3, Issue 4, 2018

\title{
PREVALENCE AND ASSOCIATED FACTORS OF ORAL NON-CANDIDA ALBICANS CANDIDA CARRIAGE IN DENTURE WEARERS IN SANA'A CITY- YEMEN \\ Khaled Abdulsalam Al-Haddad ${ }^{1}$, Omar Ahmed Esma'il Al-dossary ${ }^{2}$, Hassan A. Al-Shamahy ${ }^{3}$ iD \\ ${ }^{I}$ Department of Orthodontic Pediatric Dentistry, Faculty of Dentistry, Sana'a University, Sana 'a, Yemen. ${ }^{2}$ Medical Microbiology Clinical Immunology, Faculty of Medicine Health Sciences, Sana'a University, Republic of Yemen. ${ }^{3}$ Faculty of Medicine Heath Sciences, Sana'a University, P.O. Box 775 Sana'a, Yemen.
}

\section{ABSTRACT}

Objective: The objective of this study was to contrast the prevalence and species of colonization of Non-Candida albicans (NCAC) in the oral cavity of denture wearers and non-denture wearers; also asses associated risk factors of their colonization.

Methods: A total of 208 subjects were studied: 104 denture wearers and 104 non-denture wearers, matched by age, sex, comprised the experimental control groups, respectively. Each subject was instructed to perform oral rinsing using a phosphate-buffered saline solution, which was expectorated processed for the recovery of Candida species on on Sabouraud dextrose agar. Isolates were identified by culturing on chromogenic Candida agar noting species-specific colony characteristics.

Results: There was a significant oral carriage rate of NCAC among denture wearers $(5.83 \%$ versus $11.1 \%$ in controls $)$ with associated risk factor (5.4) $(P<0.001)$. The most common isolated NCAC were C. Krusi C. tropicalis with significant OR (5.5 4.7 respectively). When co-infections were considered, there was highly significant association of C. albicans $+C$. krusi oral colonization in cases $(\mathrm{OR}=4.56, P<0.001)$. There was a significant oral carriage rate of $N C A C$ among male denture wearers (36.9\%, $\mathrm{OR}=6.6, P<0.001)$. In addition, there was a significant rate of NCAC colonization with complete denture (rate $=50 \%$, $\mathrm{OR}=2.4, P=0.02$ ). While no significant increase associated with colonization of NCAC with partial, acrylic /or chrome cobalt denture.

Conclusion: Based on the results of this study ability of NCAC were greater in denture wearers than non-denture wearers, also greater risk of NCAC were found with males, older ages, complete denture.

Keywords: Carriage, denture, non-Candida albicans andida (NCAC), prevalence.

Article Info: Received 10 June 2018; Revised 9 July; Accepted 25 August, Available online 15 September 2018

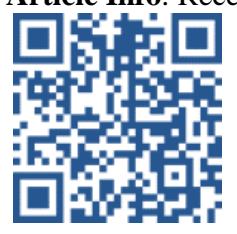

Cite this article-

Al-Haddad KA, Al-dossary OAE, Al-Shamahy HA. Prevalence and associated factors of oral non-Candida albicans Candida carriage in denture wearers in Sana'a city-Yemen. Universal Journal of Pharmaceutical Research 2018; 3(4): 7-11.

DOI: https://doi.org/10.22270/ujpr.v3i4.176

Address for Correspondence:

Prof. Hassan A. Al-Shamahy, Faculty of Medicine Heath Sciences, Sana'a University, P.O. Box 775 Sana'a, Yemen. Tel: +9671-239551, E-mail: shmahe@yemen.net.ye

\section{INTRODUCTION}

The preponderance oral yeast infections are caused by members of the genus Candida. Candidiasis is an opportunistic infection due to pathological changes in the surface of oral mucosal cavity ${ }^{1,2}$. Candidiasis patients may show various symptoms including painful sensation, burning, swallowing difficulty change of taste, but most frequently are asymptomatic ${ }^{3}$. The infection is generally treated with antifungal drugs, but in immune-compromised patients such as patients treated in intensive care units, cancer patients receiving radiation or chemotherapy, organ transplant patients HIV-positive patients' return of infections may be problem. In the last twenty years, some Candida species, including C. glabrate, C. tropicalis, C. krusei, C. parapsilosis, have been isolated with increasing frequency from cases of Candidiasis ${ }^{4,5,6}$. It is known that each species differs in the production of recognized virulence factors sensitivity to antifungal agents. Isolation identification the Candida spp. is useful in choosing correct treatment, as some species may be resistant to certain groups of antifungal drugs $^{7-9}$. Infection caused by $N C A C$, such as $C$. glabrate, C. tropicalis, C. krusei, have been found to be less response to fluconazole ${ }^{10}$. Moreover, there are reports of numerous cases describing infection colonization of immune-compromised patients on longterm treatments of oral antifungal agents, drug resistant 
C. glabrate C. krusei have been recovered from them ${ }^{11}$. As well as, host defenses have been reported to be less effective in patients infected by $C$. glabrata than $C$. albicans $^{11}$. The newer triazoles, including posaconazole voriconazole; echinocandins, caspofungin, micafungin, anidulafungin are antifungal drugs that show strong activity against Candida spp. On the other hand, echinocandins, appears to be less potent against some species, such as C. guilliermondii $C$. parapsilosis $^{8}$. As well, C. dubliniensis is very similar to $C$. albicans has been reported to have low susceptibility to azole drugs ${ }^{9,12}$.

The wearing of dentures is associated with overgrowth of Candida species, leading to denture stomatitis. Studies to identify Candida species in patients with denture stomatitis have produced contradictory results ${ }^{8}$. A number of studies assertion that a single species was responsible for the infections ${ }^{13}$ while others isolated accused multiple species of Candida ${ }^{14}$. The objective of this study was to compare the prevalence and species colonization due to NCAC in the oral cavity of denture wearers' non-denture wearers' analysis associated risk factors of their colonization.

\section{METHODS}

\section{Subject selection}

A total of two hundreds eight persons, were included in this study, 104 of them were denture wearer patients (cases group) while the other 104 adults with natural teeth (controls group), whom been selected romly from Al-Thawrah hospital, Al-Gumhory hospital Dental centers in Sana'a city, Yemen. The duration of the study was six months period, started in August 2017 ended in February 2018. Inclusion criteria for subject selection were healthy individuals with no clinical signs of Candida infection no systemic disease. In addition, individuals who smoked, currently taking antifungal, steroids, antibiotics, or immunosuppressive drugs in the past 6 months were excluded.

\section{Collection identification of samples}

Salivary samples were collected using the oral rinse technique ${ }^{15}$. In brief, each subject was asked to rinse the mouth for 60 seconds with $10 \mathrm{ml}$ of sterile phosphate-buffered saline (PBS; $0.01 \mathrm{M}$ phosphatebuffered saline solution, $\mathrm{pH}$ 7.2) expectorate the wash into a $15 \mathrm{ml}$ sterile container ${ }^{16}$. Individuals who had removable dentures were asked to take out the denture prior to samples collection. The samples were immediately transported on ice to the microbiology laboratory. Each oral rinse was centrifuged at $3500 \mathrm{rpm}$ for 10 minutes, and then the supernatant was discarded. The pellet was re-suspended in $1 \mathrm{ml}$ sterile PBS. One hundred $\mu \mathrm{l}$ of the concentrated oral rinse was inoculated onto Sabouraudus dextrose agar incubated at $37^{\circ} \mathrm{C}$ for 48 hours. The lasting samples were stored at $-20^{\circ} \mathrm{C}$. If Candida colonies appeared on the Sabouraud dextrose agar, then chromogenic Candida agar was inoculated using $100 \mu \mathrm{l}$ of the oral rinse supernatant incubated for 48 hours for colonies study. Candida species were identified by the color of the colonies using the color reference guide supplied by the manufacturer. When color identification was unclear, fermentation assay of sucrose, maltose, glucose, lactose galactose was done. The Candida species were also identified by the ability to produce chlamydo-spores on glutinous rice agar ${ }^{17}$.

Data analysis

Data were statistically analyzed using the EPI-Info program version 6.The difference in distribution of the Candida species between groups was based on comparison of frequency distributions by a chi-square test. A p value $<0.05$ was considered significant.

\section{Ethical approval}

We obtained written consent from all cases. Assent was taken from participants before collecting the specimens. The study proposal was evaluated and approved by the Ethics Committee of Faculty of Medicine Health Sciences, Sana'a University.

Table 1: The yeast distribution in different sexes of the denture wearer (cases) non denture wearer (controls) groups of the study populations.

\begin{tabular}{|c|c|c|c|c|c|c|c|c|}
\hline \multirow[t]{2}{*}{ Organisms } & \multicolumn{2}{|c|}{$\begin{array}{c}\text { Cases } \\
(\text { No. }=104)\end{array}$} & \multicolumn{2}{|c|}{$\begin{array}{l}\text { Controls } \\
(\text { No.=104 })\end{array}$} & \multirow[t]{2}{*}{ OR } & \multirow[t]{2}{*}{ CI } & \multirow[t]{2}{*}{$\chi^{2}$} & \multirow[t]{2}{*}{$P$} \\
\hline & No. & $\%$ & No. & $\%$ & & & & \\
\hline Total Non C. albicans Candida & 42 & 38.5 & 12 & 11.5 & 5 & $2.4-10.2$ & 35 & $<0.001$ \\
\hline C. krusi & 32 & 30.7 & 8 & 7.6 & 5.5 & $2.4-12.7$ & 18.8 & $<0.001$ \\
\hline C. tropicalis & 16 & 15.4 & 4 & 3.8 & 4.7 & $1.5-14.6$ & 8.4 & 0.003 \\
\hline C. glabrata & 2 & 1.9 & 2 & 1.9 & 1.03 & $0.14-7.5$ & 0.96 & 0.6 \\
\hline C. albicans + C. krusi & 22 & 21.1 & 6 & 5.8 & 4.56 & $1.7-11.7$ & 22 & $<0.001$ \\
\hline C. albicans + C. tropicalis & 8 & 7.7 & 4 & 3.8 & 2.16 & $0.6-7.4$ & 1.9 & 0.16 \\
\hline $\begin{array}{l}\text { C. albicans }+C . \text { krusi }+C . \\
\text { tropicalis }\end{array}$ & 6 & 5.7 & 0 & 0.0 & unde & & 6.5 & 0.012 \\
\hline
\end{tabular}

OR- Odds ratio $=$ Relative risk, $95 \%$ CI- 95\% Confidence intervals, $\chi^{2}$ Chi-square $=3.9$ or more is significant, $p v$ - Probability value $=0.05$ or less is significant

\section{RESULTS}

There was a significant oral carriage rate of NCAC among denture wearers (cases) equaled to $38.5 \%$ comparing with only $11.1 \%$ among non-denture wearers (controls) with OR of association equaled to 5.4 times $(P<0.001)$. There was a significant oral carriage rate of $C$. Krusei among cases (30.7\%) comparing with only $7.4 \%$ in controls with 5.5 association $(P<0.001)$. A significant oral carriage rate of $C$. tropicalis among cases $(15.4 \%$,) comparing with only $3.7 \%$ in controls with 4.7 times of association $(P=0.003)$, while no significant association with $C$. glabrata. When co-infections were considered, there was highly significant association of $C$. albicans $+C$. krusi oral colonization in cases $(\mathrm{OR}=4.56, P<0.001)$, but no significant association of $C$. albicans $+C$. 
tropicalis infection in the denture wearer (Table 1). There was a significant oral carriage rate of $N C A C$ species among male denture wearers (36.9\%) with significant association $(\mathrm{OR}=6.6, P<0.001)$. While in the females group, there was only a slightly difference between oral carriage rate of NCAC among female denture wearers comparing with non-denture wearer females. There was a highly significant association between older age groups ( $>45$ years) of cases and contract of oral NCAC colonization with OR ranged from 1.4 to 5.4 times (Table 2). When we considered type of dental prosthesis, there was a significant rate increase with complete denture. The rate was 50\%, with a highly significant association between complete denture and contract of oral NCAC colonization $(\mathrm{OR}=2.4, \quad P=0.02)$. While no significant increase associated with colonization of NCAC with partial, acrylic /or chrome cobalt denture (Table 3).

Table 2: The carriage rate of NCAC in cases controls associated OR for different sex's age groups.

\begin{tabular}{|c|c|c|c|c|c|c|c|c|c|}
\hline \multirow[t]{2}{*}{ Factors } & & \multicolumn{2}{|c|}{$\begin{array}{c}\text { Cases } \\
(n=104)\end{array}$} & \multicolumn{2}{|c|}{$\begin{array}{l}\text { Controls } \\
(n=104)\end{array}$} & \multirow[t]{2}{*}{ OR } & \multirow[t]{2}{*}{ CI } & \multirow[t]{2}{*}{$\chi^{2}$} & \multirow[t]{2}{*}{$P$} \\
\hline & & No. & $\%$ & No. & $\%$ & & & & \\
\hline Male & & $36 / 92$ & 39.1 & $8 / 92$ & 8.7 & 6.6 & $2.7-16.5$ & 23 & $<0.001$ \\
\hline Female & & $6 / 12$ & 50 & $4 / 12$ & 33.3 & 1.6 & $0.4-6.9$ & 0.5 & 0.47 \\
\hline \multirow{4}{*}{ Age group } & $<45$ years & $2 / 10$ & 20 & $2 / 10$ & 20 & 1.4 & $0.1-10$ & 0.0 & 0.97 \\
\hline & 45-54 years & $8 / 16$ & 50 & $2 / 16$ & 12.5 & 4.4 & $1.0-30$ & 4 & 0.04 \\
\hline & $55-64$ years & $16 / 32$ & 50 & $4 / 32$ & 12.5 & 4.7 & $1.4-17.4$ & 8.5 & 0.003 \\
\hline & $\geq 65$ years & $18 / 46$ & 39.1 & $4 / 46$ & 8.7 & 5.4 & $1.6-19.8$ & 10.5 & 0.001 \\
\hline Total & & $42 / 104$ & 40.4 & $12 / 104$ & 11.5 & 5.4 & $2.5-11.8$ & 23.9 & $<0.001$ \\
\hline
\end{tabular}

OR- Odds ratio $=$ Relative risk, $95 \%$ CI- 95\% Confidence intervals, $\chi^{2}$ Chi-square $=3.9$ or more is significant, $p$ v- Probability value $=0.05$ or less is significant

Table 3: The type of dental prosthesis factors that associated with colonization of NCAC among denture wearer patients.

\begin{tabular}{|c|c|c|c|c|c|c|}
\hline \multirow[t]{2}{*}{ Factors } & \multicolumn{2}{|c|}{$\begin{array}{c}\text { Positive NCAC } \\
(\mathrm{n}=42)\end{array}$} & \multirow[t]{2}{*}{ OR } & \multirow[t]{2}{*}{ CI } & \multirow[t]{2}{*}{$\chi^{2}$} & \multirow[t]{2}{*}{$\boldsymbol{P}$} \\
\hline & No. & $\%$ & & & & \\
\hline \multicolumn{7}{|c|}{ Type of dental prosthesis } \\
\hline Complete $n=46$ & 24 & 52.2 & 2.4 & 1.0.- 5.8 & 4.7 & 0.02 \\
\hline Partial $n=58$ & 18 & 31 & 0.4 & $0.16-0.9$ & 5.4 & 0.02 \\
\hline Acrylic $n=74$ & 30 & 40.5 & 1.02 & $0.4-2.6$ & 0.00 & 0.97 \\
\hline Chrome cobalt $n=38$ & 12 & 31.6 & 0.73 & $0.3-1.8$ & 0.54 & 0.46 \\
\hline
\end{tabular}

OR- Odds ratio $=$ Relative risk, $95 \%$ CI- 95\% Confidence intervals, $\chi^{2}$ Chi-square $=3.9$ or more is significant, $p$ v- Probability value $=0.05$ or less is significant

\section{DISCUSSION}

NCAC strains, however, are isolated in growing numbers in medically compromised patients. These strains might cause systemic infections are frequently resistant to commonly used antifungal agents such as fluconazole ${ }^{18,19}$. In the present study, there was a significant oral carriage rate of NCAC among denture wearers $(38.5 \%)$ comparing with only $11.1 \%$ among non-denture wearers. In addition, there was a highly significant association between denture wear and contract of oral NCAC with OR equaled to 5.4 times $(P<0.001)$. When single species of NCAC was considered, there was a significant oral carriage rate of C. Krusei among cases (30.7\%) comparing with only $7.4 \%$ in controls with 5.5 association $(P<0.001)$ followed by $C$. tropicalis $(15.4 \%)$ comparing with only $3.7 \%$ in controls with 4.7 times of association $(P=0.003)$, while no significant association with $C$. glabrata and absent of $C$. parapsilosis (Table 1). Current results were different from that reported elsewhere, in which $C$. tropicalis was the most common NCAC, followed by $C$. glabrata, while $C$. parapsilosis were rare isolated in healthy oral colonization or as a cause of illnesses in patients ${ }^{19}$.

When co-infections were considered, there was highly significant association of $C$. albicans $+C$. krusi oral colonization in cases $(\mathrm{OR}=4.56, P<0.001)$, but no significant association of $C$. albicans $+C$. tropicalis infection in the denture wearer (Table 1). The carriage rates of single multiple Candida species were reported to be significantly higher in denture wearers ${ }^{20}$. As it is known, NCAC may be capable of metabolizing ethanol to carcinogenic acetaldehyde can thus progress oral upper gastrointestinal tract cancer. So, 38.5\% of current studied individuals having dentures under possible risk of oral upper gastrointestinal tract cancer. Consequently, more focus should be placed on diagnosis treatment of oral Candida infections, also on other Candida species than $C$. albicans as it has been recommended $^{19,20}$.

The highly significant association between denture wear a contract of oral NCAC with the high risk (OR equaled to 5.4 times) can be explained by the fact that one of the most important virulence factors of NCAC is its ability to form biofilms, which has an important clinical consequence, as it confers resistance to antifungal therapy capacity for yeast cells within the biofilms to resist host immune defenses ${ }^{23-26}$. A second explanation might be due to that changes in the oral environment affected by tooth loss or denture wearing can cause changes in oral microflora ${ }^{20}$. Also in this study, the data supported the rejection of the null hypothesis, which states that there would be no difference between male and female denture wearers in 
terms of the colonization by NCAC of the inner surfaces of dentures and the surrounding attachments. While there was a significant association between denture wearing in male group a contract of oral carriage of $\mathrm{NCAC}$ with $\mathrm{OR}$ equaled to 6.6 times, $(\mathrm{CI}=2.7-16.5, P<0.001)$. Current result was different from that reported by $\operatorname{Thein}^{27}$ in which similar colonization rate was observed in both adult sexes. Moreover, there was a trend of rising of oral NCAC colonization with increasing age in cases and controls (Table 1), in which the highest rate of NCAC was in the older age groups. Current study's result, also, was similar to that reported by Chopde et al., ${ }^{28}$ in which extremes of age is more susceptible to oral NCAC colonization. This result can be explained by that the elderly generally suffered from systemic illnesses, changes in nourishment and their salivary characteristics $^{28,29}$. Advancing age was also a risk factor for denture stomatitis in the elderly, because cell-mediated immunity, which provides protection against Candidal infection, declines with age. According to Dar-odeh Shehabi, some oral environmental factors, such as un-stimulated salivary flow rate age of subjects, were associated with higher numbers of microbes in the saliva of complete denture wearers ${ }^{30}$. Those authors suggested that a reduction in the salivary flow rate with aging induced an increase in concentration of microbes in saliva ${ }^{31}$.

\section{CONCLUSION}

Based on the results of this study ability of NCAC were greater in denture wearers than non-denture wearers, also greater risk of NCAC were found with males, older ages, complete denture. In addition, current results are important for the development of strategies for eliminate these indicators of risk significantly reduce NCAC colonization oral Candida infections in denture wearers.

\section{ACKNOWLEDGEMENTS}

Authors acknowledge the financial support of Sana'a University, Yemen.

\section{AUTHOR'S CONTRIBUTION}

The manuscript was carried out, written, and approved in collaboration with all authors.

\section{CONFLICT OF INTEREST}

No conflict of interest associated with this work.

\section{REFERENCES}

1. Gonsalves WC, Chi AC, Neville BW. Common oral lesions: Part I. Superficial mucosal lesions. Am Fam Physician 2007; 75:501-7.

2. Da Costa SC, De Resende MA, Lyon JP, Totti VMG, Munhoz MF. Predisposing conditions for Candida spp. carriage in the oral cavity of denture wearers individuals with natural teeth. Can J Microbiol 2006; 52:462-7. https://doi.org/10.1139/w05-148

3. Samaranayake LP. Host factors oral Candidiasis. In: Mac Farlane TW, Samaranayake LP, editors. Oral cidosis. London: Butterworth and Company Ltd. 1990; 66-103. https://doi.org/10.1080/10158782.2011.11441414
4. Samaranayake LP. Superficial oral fungal infections. Curr Opin Dent 1991; 1:415-22.

5. Scully C, El-Kabir M, Samaranayake LP. Candida oral cidosis: a review. Crit Rev Oral Biol Med 1994; 5:125-57. https://doi.org/10.1177/10454411940050020101

6. Borg-von ZM, Kunz L, Rüchel R, Reichard U, Weig M, Gross U. Epidemiology antifungal susceptibilities of Candida spp. to six antifungal agents: results from a surveillance study on fungaemia in Germany from July 2004 to August 2005. J Antimicrob Chemother 2007; 60:424-8. https://doi.org/10.1093/jac/dkm145

7. Kuriyama T, Williams DW, Bagg J, Coulter WA, Ready D, Lewis MA. In vitro susceptibility of oral Candida to seven antifungal agents. Oral Microbio Imm 2005; 20:349-53. https://doi.org/10.1111/j.1399-302X.2005.00236.x

8. Moudgal V, Little T, Boikov D, Vazquez JA. Multiechinocin- Multiazole-resistant Candida parapsilosis isolates serially obtained during therapy for prosthetic valve endocarditis. Antimicrob Agents Chemother 2005; 49:767-9. https://doi.org/10.1128/AAC.49.2.767-769.2005

9. Sullivan DJ, Moran GP, Pinjon E, Al-Mosaid A, Stokes C, Vaughan $\mathrm{C}$, et al. Comparison of the epidemiology, drug resistance mechanisms, virulence of Candida dubliniensis Candida albicans. FEMS Yeast Res 2004; 4:369-76. https://doi.org/10.1016/S1567-1356(03)00240-X

10. Sheehan DJ, Hitchcock CA, Sibley CM. Current emerging azole antifungal agents. Clin Microbiol Rev. 1999; 12:40-79. PMID: 9880474

11. Mendling W, Koldovsky U. Immunological investigations in vaginal mycoses. Mycoses 1996; 39: 177-83.

https://doi.org/10.1111/j.1439-0507.1996.tb00122.x

12. Schubert S, Rogers PD, Morschhäuser J. Gain of- function mutations in the transcription factor MRR1 are responsible for over expression of the MDR1 efflux pump in fluconazole-resistant Candida dubliniensis strains. Antimicrob Agents Chemother 2008; 52:4274-80. https://doi.org/10.1128/AAC.00740-08

13. Kreher JM, Graser GN, Helman SL, Eisenberg AD. Oral yeasts, mucosal health, drug use in an elderly denturewearing population. Spec Care Dentist 1991; 11:222-6. https://doi.org/10.1111/j.1754-4505.1991.tb01483.x

14. Cumming CG, Wight C, Blackwell CL, Wray D. Denture stomatitis in the elderly. Oral Microbiol Immunol 1990; $5: 82-5$.

15. Coulter WA, Kinirons MJ, Murray SD. The use of a concentrated oral rinse culture technique to sample oral Candida lactobacilli in children, the relationship between Candida Lactobacilli levels dental caries experience: A pilot study. Int J Paediatr Dent 1993; 3:17-21. https://doi.org/10.1111/j.1365-263x.1993.tb00042.x

16. MacFarlane TW, Samaranayake LP, Williamson MI. Comparison of Sabouraud dextrose Pagano-Levin agar media for detection isolation of yeasts from oral samples. $\mathbf{J}$ Clin Microbiol 1987; 25:162-4. PMID: 3539988

17. Staib $\mathrm{P}$, Morschhäuser J. Chlamydospore formation in Candida albicans Candida dubliniensis - an enigmatic developmental programme. Mycoses 2007; 50:1-12. https://doi.org/10.1111/j.1439-0507.2006.01308.x

18. Lalla, RV; Patton, LL; Dongari-Bagtzoglou, A. Oral Candidiasis: pathogenesis, clinical presentation, diagnosis treatment strategies. J California Dent Assoc 2013; 41 (4): 263-8. PMID: 23705242

19. Kourkoumpetis, Themistoklis. Candida infection colonization among non-trauma emergency surgery patients. Virulence 2010; 359-366. https://doi.org/10.4161/viru.1.5.12795

20. Jenkinson HF, Douglas LJ. Interactions between Candida species bacteria in mixed infections. In: Brogden KA, Guthmiller JM, editors. Polymicrobial diseases. Washington DC: ASM Press. 2002; 357-73. 
21. Manolakaki D, Velmahos G, Kourkoumpetis T, Chang Y, Alam HB, De Moya MM, Mylonakis. E. Candida infection colonization among trauma patients. Virulence 2010; 1 (5):367-375. https://doi.org/10.4161/viru.1.5.12796

22. dEnfert C; Hube B (editors). Candida: Comparative Functional Genomics. Caister Academic Press. ISBN 978-1904455-13-4, 2007.

23. Pereira-Cenci T, Del Bel Cury AA, Crielaard W, Ten Cate JM. Development of Candida-associated denture stomatitis: new insights. J Appl Oral Sci 2008; 16:86-94. https://doi.org/10.1590/s1678-77572008000200002

24. Coogan MM, Fidel PL Jr, Komesu MC, Maeda N, Samaranayake LP. Candida mycotic Infections. Adv Dent Res 2006; 19:130-8. https://doi.org/10.1177/154407370601900124

25. Costa CR, Cohen AJ, Fernes OF, Mira KC, Passos XS, Souza LK, et al. Asymptomatic oral carriage of Candida species in HIV-infected patients in the highly active antiretroviral therapy era. Rev Inst Med Trop Sao Paulo 2006; 48:257-61. https://doi.org/10.1590/S0036-46652006000500004

26. Jin YY, Yip HK, Samaranayake YH, Yau JY, Samaranayake LP. Biofilm-forming ability of Candida albicans is unlikely to contribute to high levels of oral yeast carriage in cases of human immunodeficiency virus infection. J Clin Microbiol 2003; 41:2961-7.

https://doi.org/10.1128/JCM.41.7.2961-2967.2003

27. Thein ZM, Samaranayake YH, Samaranayake LP. In vitro biofilm formation of Candida albicans non-albicans Candida species under dynamic anaerobic conditions. Arch Oral Biol. 2007; 52:761-7.

https://doi.org/10.1016/j.archoralbio.2007.01.009

28. Chopde N, Jawale B, Phare A, Chaudhari L, Hiremath V, Redasani R. Microbial colonization their relation with potential cofactors in patients with denture stomatitis. J Contemp Dent Pract 2012; 13:456-9.

https://doi.org/10.1128/mSphere.00215-16

29. Semlali A, Killer K, Alanazi H, Chmielewski W, Rouabhia M. Cigarette smoke condensate increases C. albicans adhesion, growth, biofilm formation, EAP1, HWP1 SAP2 gene expression. BMC Microbiol 2014; 14:61. https://doi.org/10.1186/1471-2180-14-61

30. Dar-odeh NS, Shehabi AA. Oral Candidiasis in patients with removable dentures Mycoses 2003; 46:187-19. https://doi.org/10.1046/j.1439-0507.2003.00871.x

31. Penha SS, Birman EG, Silveira FR, Paula CR. Frequency enzymatic activity (proteinase phospholipase) of Candida albicans from edentulous patients, with without denture stomatitis. Pesq Odontol Bras 2000; 14:119-122. https://doi.org/10.1590/S1517-74912000000200005 